\title{
Hantavirus: A Literature Search for Scientific Production of the Infection Using Bibliometric Analysis
}

\author{
Vasna Joshua ${ }^{1}$, Satish $\mathbf{S}^{1^{*}}$
}

1. ICMR, National Institute of Epidemiology, Ayapakkam, Chennai, 600077 Tamilnadu, INDIA

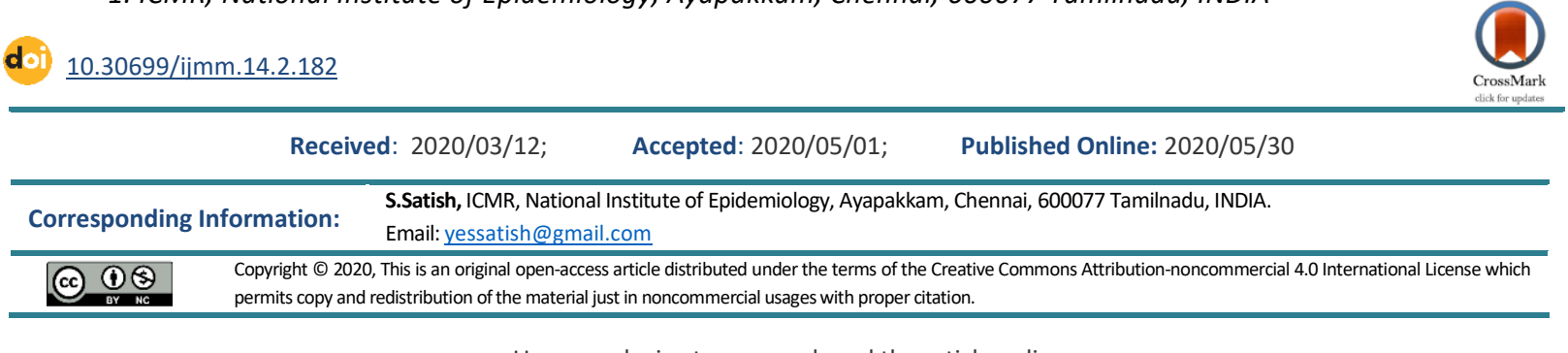

Use your device to scan and read the article online

Download citation: BibTeX | RIS | EndNote | Medlars | ProCite | Reference Manager | RefWorks

Send citation to: 8 Mendeley 2 zotero $\mathbb{H}_{\text {RefWorks }}$

Joshua V, S S. Hantavirus: A Literature Search for Scientific Production of the Infection Using Bibliometric Analysis. Iran J Med Microbiol. 2020; 14 (2) :182-184

\section{Dear Editor}

The novel Coronavirus (COVID-19), which emerged from the Wuhan City of China was first reported to the World Health Organization on 31December 2019. It has affected 205 countries and territories and infected more than 1,141,425 people worldwide, and claimed over 61,205 lives (1). Amidst this pandemic outbreak, the death of a person from Yunnan province by Hantavirus also became a source of panic for the humankind. Eventually it made us to search literature for global publication of Hantavirus infection using the three databases: Scopus, Web of science (WoS) and PubMed.

In 1978, in South Korea, near the Hantan river, an outbreak of Hemerologic fever occurred. The causative agent was isolated from a small infected field rodent. The virus was named by its birth place as 'Hanta anvirus'. Later in 1993 the outbreak in the four corner region of Southwestern United States that caused serious respiratory distress in infected patients was called as hantavirus pulmonary syndrome (HPS). Eventually it led to the discovery of hantavirus genus of more than twenty-one species and more than 30 genotypes (2).

We explored three main biomedical databases globally namely Scopus, Web of Science (WoS) and PubMed. using the search strategy as "Hantavirus" in the title. All the research outputs were downloaded on $27^{\text {th }}$ March 2020 published from 1 Jan 1999 to $27^{\text {th }}$ March 2020 (22 years).
Globally number of research articles retrieved by the three databases were 1519 (WoS), 1566 (PubMed) and 1348 (Scopus). On an average the number of research articles identified by WoS, PubMed and Scopus were 69, 71 and 61 respectively per year. PubMed identified the maximum number of articles. Examining all three databases, the growth pattern of the Hantavirus articles was neither increasing nor decreasing over years (Fig I). The growth was on the increase during the years 2007, 2014 and 2019.

The major five productive countries were from USA, Finland, Germany, China and Sweden (Fig II). Considering WoS, 31.8\% from USA, Finland $12.7 \%$, Germany $12.2 \%$, China $4.9 \%$ and Sweden 9.5\%; followed by PubMed, $18.2 \%$ from USA, Finland 9.1\%, Germany $8.1 \%$, China 7.9 $\%$ and Sweden 5.1; and Scopus, 26.7\% from USA, 11.6\% Finland, 11\% Germany, 9.6\%China and 8.8\% Sweden.

The reported number of cases of Hantavirus Infection in the United States (1999-2018) through the Nationally Notifiable Disease Surveillance System (NNDSS) (3) is shown in Fig I. Also the European Centre for Disease Prevention and Control (ECDC) surveillance report 2015 (4) shows the number of Hantavirus infection cases for the period 2011-2015 for European countries. The second productive country Finland showed an increased number (2089 cases) during the year 2014. It can be justified that, whenever more number of cases occur as an outbreak, there appears a growth in the number of research articles. 


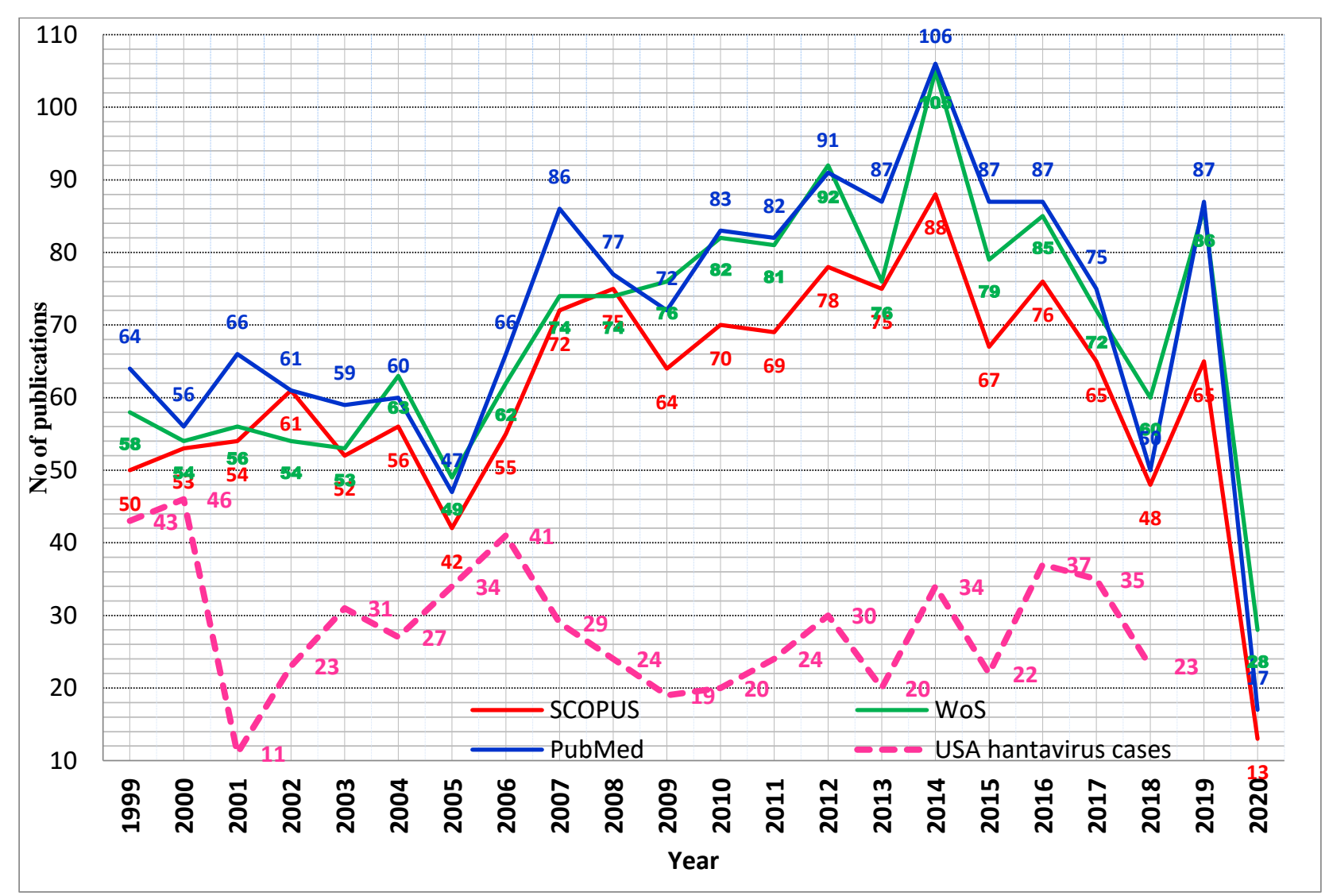

Figure 1. Year wise distribution of Hantavirus research publications globally identified by WoS, Scopus and PubMed, 1999March 2020

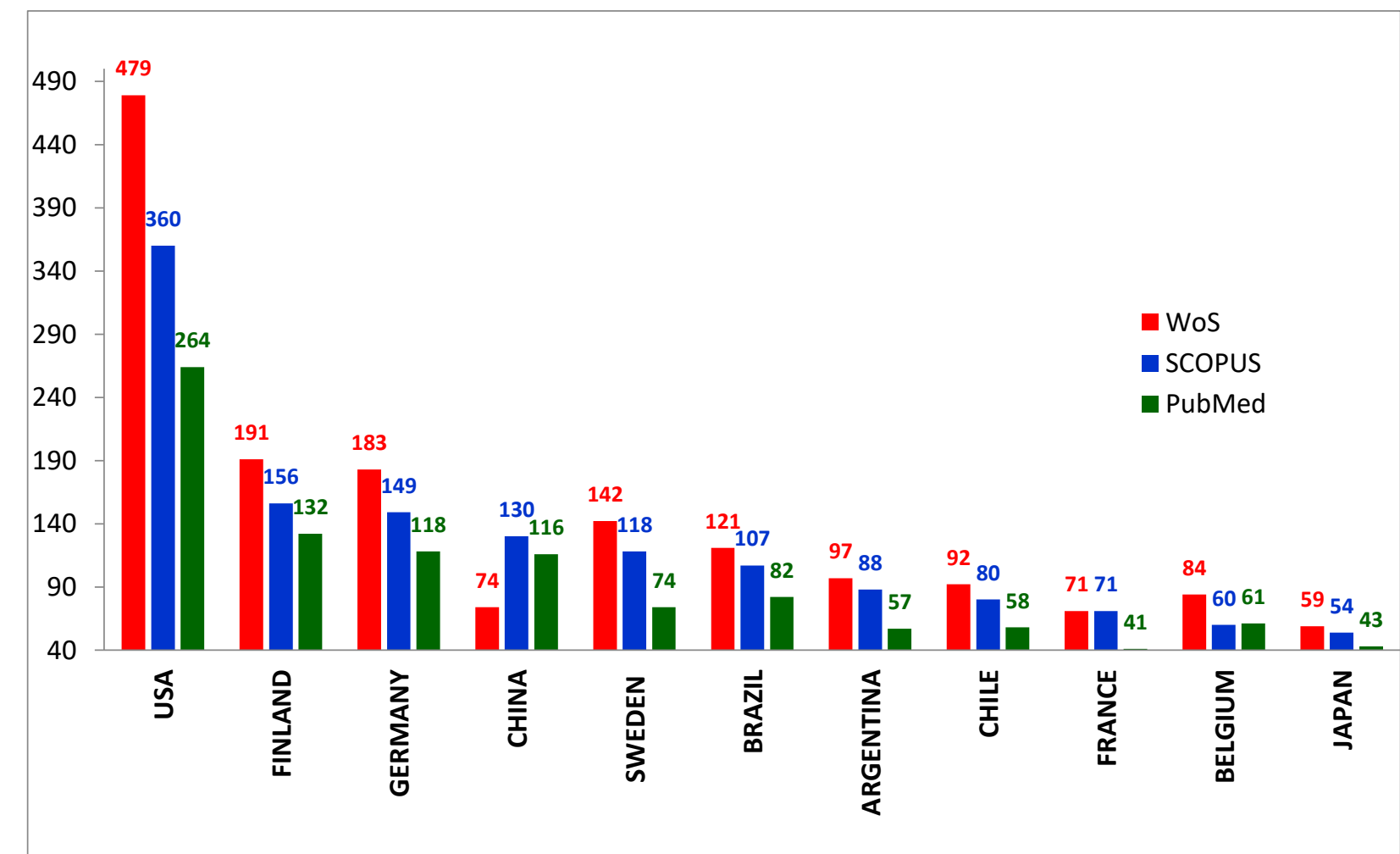

Figure 2. Hantavirus leading research articles by the country identified by WoS, Scopus and PubMed, 1999- March 2020 
To conclude based on the three databases, the growth pattern of the Hantavirus research articles was not steady. The pattern showed some fluctuations, the magnitude of the output got raised followed by an outbreak where in the scientific community became active and it was on lower side until a further outbreak. The country USA has contributed more publications may be due to the reason of the first outbreak of unknown origin happened and moreover it is a predominant country for scientific research as shown various bibliometric analysis (5-10)

Since from the first outbreak of Hanta pulmonary syndrome (HPS) in May 1993, several Cases of HPS outbreak from related hantaviruses have been documented in various countries like Argentina, Brazil, Canada, Chile etc. (1). Consequently, it would have led to more research and as a result many scientific outputs are published. Any scientific research output disseminates one or more of the following: epidemiology of the disease, severity of the disease and its impact, the emergency response required, remedial measures, probable research collaborations, development of medicines and vaccines. Hence Hantavirus research outputs indicates the scientific community is dynamic and active.

\section{Acknowledgment}

The authors thank all those who helped them writing this paper.

\section{Conflict of Interest}

Authors declared no conflict of interests.

\section{Rerefencess}

1. Woldmeter.https://www.worldometers.info/corona virus/ [Accessed 5 April 2020]
2. Mohammed M. Hantavirus. Clinics in Laboratory $\begin{array}{ll}\text { Medicine. } & 2010 \\ \text { 30(1):67-91. }\end{array}$ [DOI:10.1016/j.cll.2010.01.004] [PMID] [PMCID]

3. Hantavirus.https://www.cdc.gov/hantavirus/surveill ance/index.html [Accessed 4 April 2020].

4. AER.Hantavirusinfection.https://www.ecdc.europa. eu/sites/default/files/documents/AER_for_2015hantavirus.pdf [Accessed 4 April 2020].

5. Sivaprakasam S, Joshua V. Nipah Virus: An Exploratory Scientometrics Analysis, 1999-2018. Journal of Scientometric Research. 2019;8(2):109116. [DOI:10.5530/jscires.8.2.17]

6. Zyoud, S.H. Global research trends of Middle East respiratory syndrome coronavirus: a bibliometric analysis. BMC Infect Dis 2016; 16, 255. [DOI:10.1186/s12879-016-1600-5]

7. Patino-Barbosa AM, Bedoya-Arias JE, CardonaOspina JA, Rodriguez-Morales AJ:Bibliometric assessment of the scientific production of literature regarding Mayaro. J InfectPublic Health 2015. [DOI:10.1016/j.jiph.2015.10.001] [PMID]

8. Zyoud SH, Al-Jabi SW, Sweileh WM, Awang R, Waring WS. Bibliometric profile of the global scientific research on methanol poisoning (1902-2012). J Occup Med Toxicol. 2015;10:17. [DOI:10.1016/i.jiph.2015.10.001] [PMID]

9. Zyoud SH, Al-Jabi SW, Sweileh WM, Awang R, Waring WS. Global research productivity of $\mathrm{N}$-acetylcysteine use in paracetamol overdose: A bibliometric analysis (1976-2012). Hum Exp Toxicol. 2015;34(10):1006- 16. [DOI:10.1177/0960327114565494] [PMID]

10. Sweileh WM, Zyoud SH, Al-Jabi SW, Sawalha AF. Contribution of Arab countries to breast cancer research: comparison with non-Arab Middle Eastern countries. BMC Womens Health. 2015;15:25. [DOI:10.1186/s12905-015-0184-3] [PMID] [PMCID] 